\title{
Acceleration in Decrease of Maternal Mortality on Developing
}

\section{Regions}

Keman $S^{*}$

Universitas Airlangga, Indonesia

${ }^{*}$ Corresponding author: Soedjajadi Keman, Universitas Airlangga, Indonesia, Tel: +62-31-5920948; E-mail: soedja_keman@fkm.unair.ac.id

\author{
Editorial \\ Volume 2 Issue 1
}

Received Date: February 15, 2018

Published Date: February 22, 2018

DOI: $10.23880 /$ phoa-16000117

\section{Editorial}

United Nations Sustainable Development Goal (UN SDG) No. 3 on maternal health stated that maternal mortality has fallen by almost 50 per cent since 1990, but maternal mortality ratio - the proportion of mothers that do not survive childbirth compared to those who do - in developing regions is still 14 times higher than in the developed regions. More women are receiving antenatal care. In developing regions, antenatal care increased from 65 per cent in 1990 to 83 per cent in 2012, but only half of women in developing regions receive the recommended amount of health care they need.

Maternal death has become an important issue in the effort to achieve attainable health status. The Millennium Development Goal's (MDG's) No. 5 was targeted to increase well-being of birthing women with maternal mortality rate (MMR) indicators. The goal of MDGs 5 was to reduce the MMR up to 75\% started from 1990-2015 (United Nation, 2000). In 1990, the MMR of Indonesia was $408 / 100,000$ live births, and it was expected to drop to $102 / 100.000$ live births by 2015. Unfortunately, the target was not achieved. Indonesia has not been exempted from the high maternal mortality rate. Indonesia has recorded the highest number of pregnant women dying during deliveries in Asia. Based on National Demographic Health Survey (SDKI) in 2007, the MMR was $228 / 100,000$ live births. Although significant reduction has been achieved, the figure is still high.

Most of maternal deaths were caused by hemorrhage, hypertension in pregnancy, infections, etc. Some maternal deaths were also caused by indirect causes. In 2010, 80.70 $\%$ deliveries were carried out at home, and $24.37 \%$ of the deliveries were assisted by unskilled maternity assistant. Focus was placed to identify the causes of maternal deaths in the developing region. It was related to health behavior.

Behavior and beliefs are shaped in a social cultural setting, while health promotion for behavioral change is more effective to occur when social environment is modified, not limited only to individual factor. The social ecological model of health behavior states that some factors influence health behavior, namely: (1) intrapersonal (individual) which covers knowledge, behavior, and individual skills; (2) The second factor is interpersonal factor which covers family, friends, and colleagues. They have strong influences to health behavior; (3) Institutional factor - most of human life occurs in institutional settings, for instance work places, particularly educational institutions and business institutions, and health institutions. They have strong influences on health and other health related behavior; (4) The fourth factor is communal factor which covers organizations in a community, and health institutions could cooperate to promote health goals. The promotion can be carried out through church, mosque, etc. On the contrary, communal factor can also obstruct all efforts to promote health behavior; (5) Public policy and birthing insurance package provided by government. Thus, the height of MMR in the developing region is not observed based on individual factor (intrapersonal), but also other factors like interpersonal (family), institutional, and communal factors. Intrapersonal factor covers: age - too young ( $<20$ years), too old $(>35$ years), too near $(<2$ years), too much ( $>4$ children).

Education, job, knowledge, behavior, value, self efficacy, and access to health care centre (distance and time to spend), as well as reproduction characteristic: pregnancy 
frequencies, paritas, first marriage age, height, weight gain, and abortus. Environmental factor, particularly social environment (interpersonal/family) in terms of responsibility of family in recognizing or identifying problems faced by pregnant women, decision making to obtain health care services, and capacity of the family in providing nursing care. Modification of the environment, health facility utility, perception of susceptibility, subjective norms, and perceived control. Institutional factor has relation to perception of pregnant women on the performance health workers in providing services during pregnancies, delivery and termination of pregnancy (post partum), dimension of reliability, assurance, tangible, empathy and responsiveness. This includes the capacity of the health workers to screen risk factors on pregnant and birthing women. While communal factor relates to how organizations in a community assist nursing care of pregnant women.

To reduce the MMR, the governments in developing regions have to develop some programs and facilities of success through health services: (1) First visit: access or first contact of skilled health worker with pregnant women in the provision of standarized, integrated and comprehensive services; (2) Four or more contacts with skilled health workers to obtain standaraized, integrated and comprehensive services; (3) Decision on delivery place in a standardized health facility; (4) Delivery assistance provided by skilled health workers in standardized health facility (health center with basic emergency obstetric and neonates care); (5) Post partum visits: starting from 6 hours after termination of a delivery up to 42 days after the termination, at least 3 times during the post partum period; (6) Family planning for post partum mothers or husbands after the termination. These situations should be put into consideration in the further intervention.

The reduction of MMR needs serious attention in order to achieve the targeted goals. In communities, there are institutions formed by and for communities. They are called villages alert and integrated health services station. These two institutions are used to empower a community members' participation. In practice, however, the two institutions operate separately. They should have been integratedly and comprehensively operated. A lot of efforts have been done to reduce the MMR in cooperation with international agencies supports. Among others providing support on strengthening health workers capacity in existing program such as Delivery Plan and Prevention of Complication Program (P4K), Normal Delivery Nursing Care (APN), PPGDON, Basic Emergency Obstetric and Neonates Care (BEONC) and Comprehensive Emergency Obstetric and Neonatal Care (CEmONC). To reduce maternal mortality rate in developing region, all efforts should be carried out comprehensively noticing various related factors influence them. Thus, a research should be carried out on development approach of social ecological model of health behavior in developing regions with special objective i.e. analizing the reduction of the maternal mortality rate based on following indicators: access to first visit, antenatal nursing care, delivery place, delivery assistance by skilled health workers, complication of nursing care, post partum visits, as well as family planning in the developing regions. 